\title{
Procuring Covid-19 Vaccine and the Contemporary Geopolitical Paradigm for Bangladesh
}

http://doi.org/10.21272/bel.5(4).118-126.2021

Kazi Md Fahim Ahmed, ORCID: https://orcid.org/0000-0001-7194-8067

MBA, BA (Hon) Business Studies, Cardiff Metropolitan University (UK), Senior Lecturer, College of Business Administration, IUBAT, Bangladesh

\begin{abstract}
Covid-19 has brought unexpected social, political, and economic interruptions to the world, causing endless suffering to people's lives. As of 19 December 2021, Covid-19 has taken away more than 5 million lives and infected more than 274 million people worldwide. Although many medicines are tested, there is barely any reliable and effective treatment found. The only hope to get out of this pandemic remains concentrated on "Vaccines". As the nations develop and distribute the Covid-19 vaccines, a potential threat becomes the utilization of vaccine distribution as a soft power tool. So, the major challenge this pandemic has brought is securing vaccine procurement worldwide. Bangladesh, the south Asian developing country, faced a vaccine shortage too. It had to go through various geopolitical struggles and diplomacies to procure vaccines. The fundamental purpose of this study is to review the vaccine procurement opportunities and their relation to the contemporary geopolitical paradigm of Bangladesh. Relevant works of literature consist of journal articles, government statements from multiple countries are reviewed throughout the case. From the beginning to the end of the case, it has been observed that there was a geopolitical power demonstration between India and China regarding the Covid-19 vaccine distribution in Bangladesh. The strong political relation with China, effective diplomacy with the US Biden administration, and a successful diplomatic effort in Japan finally helped Bangladesh to procure a sufficient vaccine for the moment. The research is significant because it connects the pandemic and geopolitics. Although the Covid-19 pandemic is stated as a humanitarian crisis by the great nations, it is clear that it has become an opportunity for many to influence the geopolitical paradigm. If the pandemic has to end, it is vital to distribute vaccines equally throughout the world. The research finds a relation of geopolitical influence with vaccine procurement which destroys equality and reduces the chance of ending the pandemic. This research will bring attention to this important issue in front of the world. In addition, based on this study, other in-depth research could be formed to reduce this global problem.
\end{abstract}

Keywords: Bangladesh, Covid-19, China Vaccine, India, Geopolitics, Pandemic, Procurement.

JEL Classification: I14, I18.

Cite as: Ahmed, K.M.F. (2021). Procuring Covid-19 Vaccine and the Contemporary Geopolitical Paradigm for Bangladesh. Business Ethics and Leadership, 5(4), 118-126. http://doi.org/10.21272/bel.5(4).118-126.2021.

Received: 05 November 2021

Accepted: 07 December 2021

Published: 30 December 2021

Copyright: (C) 2021 by the author. Licensee Sumy State University, Ukraine. This article is an open access article distributed under the terms and conditions of the Creative Commons Attribution (CC BY) license (https://creativecommons.org/licenses/by/4.0/).

\section{Introduction}

Pandemics such as Covid-19 once in a century bring unprecedented social, political, and economic interruptions on a global scale. This type of phenomenon causes endless suffering to people's lives. As of 19 December 2021, Covid-19 has taken away more than 5 million lives and infected more than 274 million people worldwide (The Visual and Data Journalism Team, 2021). A World Bank statistic shows that in 2020 the world economy shrank 4.3 percent as the pandemic affected (World Bank, 2021). According to the IMF- International Monetary Fund report, the GDP loss due to the Covid-19 is approximate 9 trillion US dollars and around 115M people have faced severe poverty during the pandemic (The Independent Panel, 2021). COVID-19 is a genetically homologous category to the pathogen SARS-CoV-2 (severe acute respiratory syndrome coronavirus) (Wu, F. et al., 2020). It works the same way the SARS-CoV does by binding with Angiotensinconverting enzyme 2 (ACE 2) (Lan, J. et al., 2020). An antiviral medicine called 'Remdicivir' has significantly reduced the patients' recovery time and mortality rate (Beigel, J.H. et al., 2020), but the patients who are highly affected by the virus are not effectively treatable by this antiviral medicine (Wang, Y. et al., 2020). Drugs like 'Remdisivirs' are used in particular cases, but the effective result is not found in general yet. 
It takes the world to rely on the only escape available - 'Vaccines'. Although vaccine development is a complicated issue, worldwide procurement and distribution are even tougher (Jieliang Wang et al., 2020). The major challenge this pandemic has brought is securing vaccine procurement worldwide (Fonseca, E. Md. et al., 2021). As the nations develop and distribute the Covid-19 vaccines, a potential threat becomes vaccine distribution as a soft power tool. The willingness to provide and distribute vaccines has been speculated to relay to geopolitical issues like it is observed in India and China. Emphasizing geopolitical issues over humanitarian issues is becoming a more significant risk (Lambert, R., Shah, C., Weiner, J. 2021). In the context of geopolitical dominance of great power of the world, no wonder vaccine is becoming more and more of a tool of power politics rather than a global public asset for saving precious lives (Vankovska, B., 2021). Bangladesh, the south Asian developing country with a population of approximately 164.69, started vaccination on 27 January 2021 with the Serum Institute's Oxford AstraZeneca vaccine (Dhaka Tribune. 2021d), faced a vaccine shortage, and later procured Pfizer, Moderna, Sinopharm, and Sinovac vaccines from various sources. The total number of 1 st dose (Figure 1) and 2nd dose (Figure 2) of different vaccines are shown below.

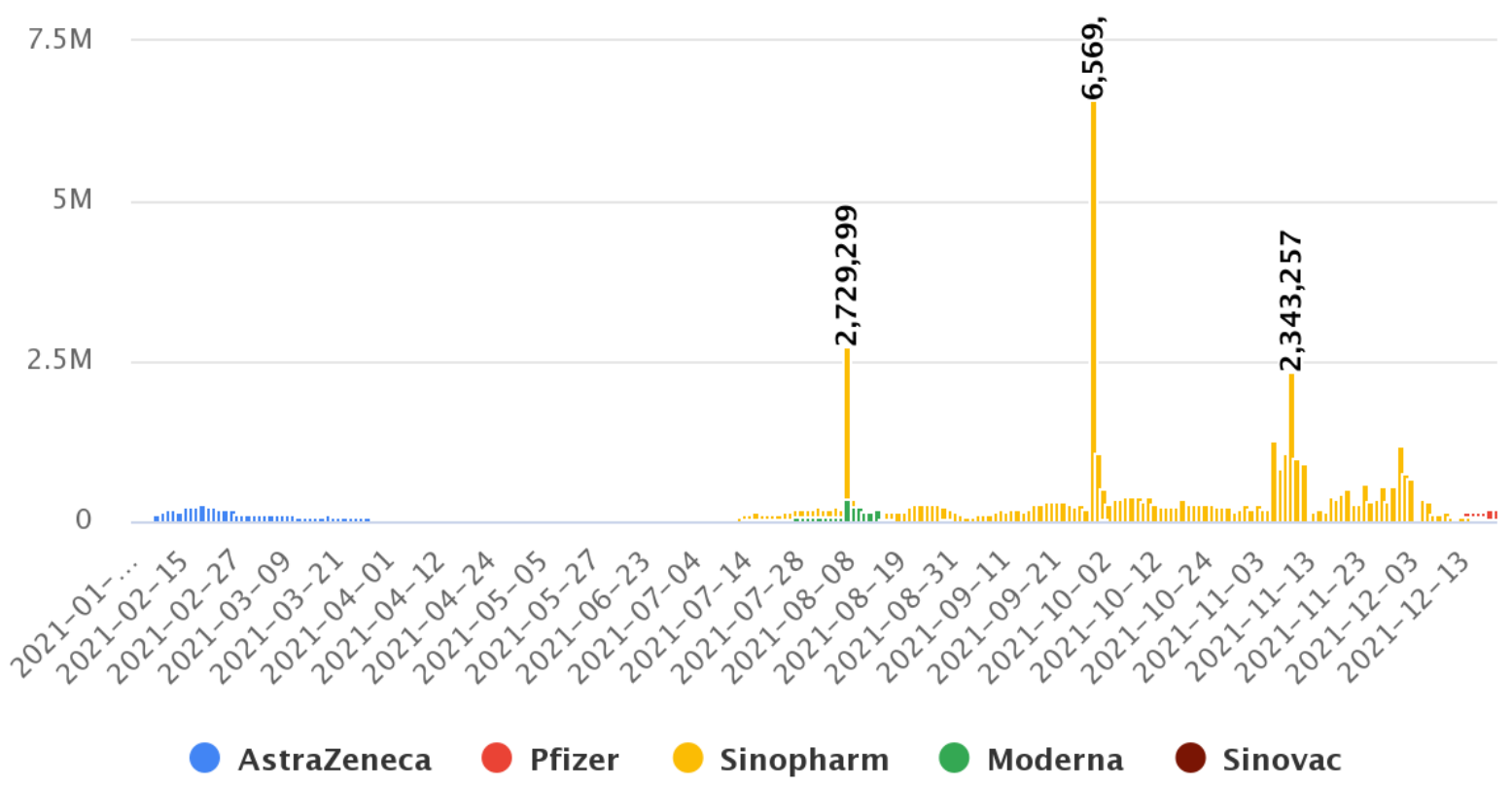

Figure 1. The $1^{\text {st }}$ Dose Vaccines Administered in Bangladesh

Source: Covid19 vaccine Dashboard, 2021

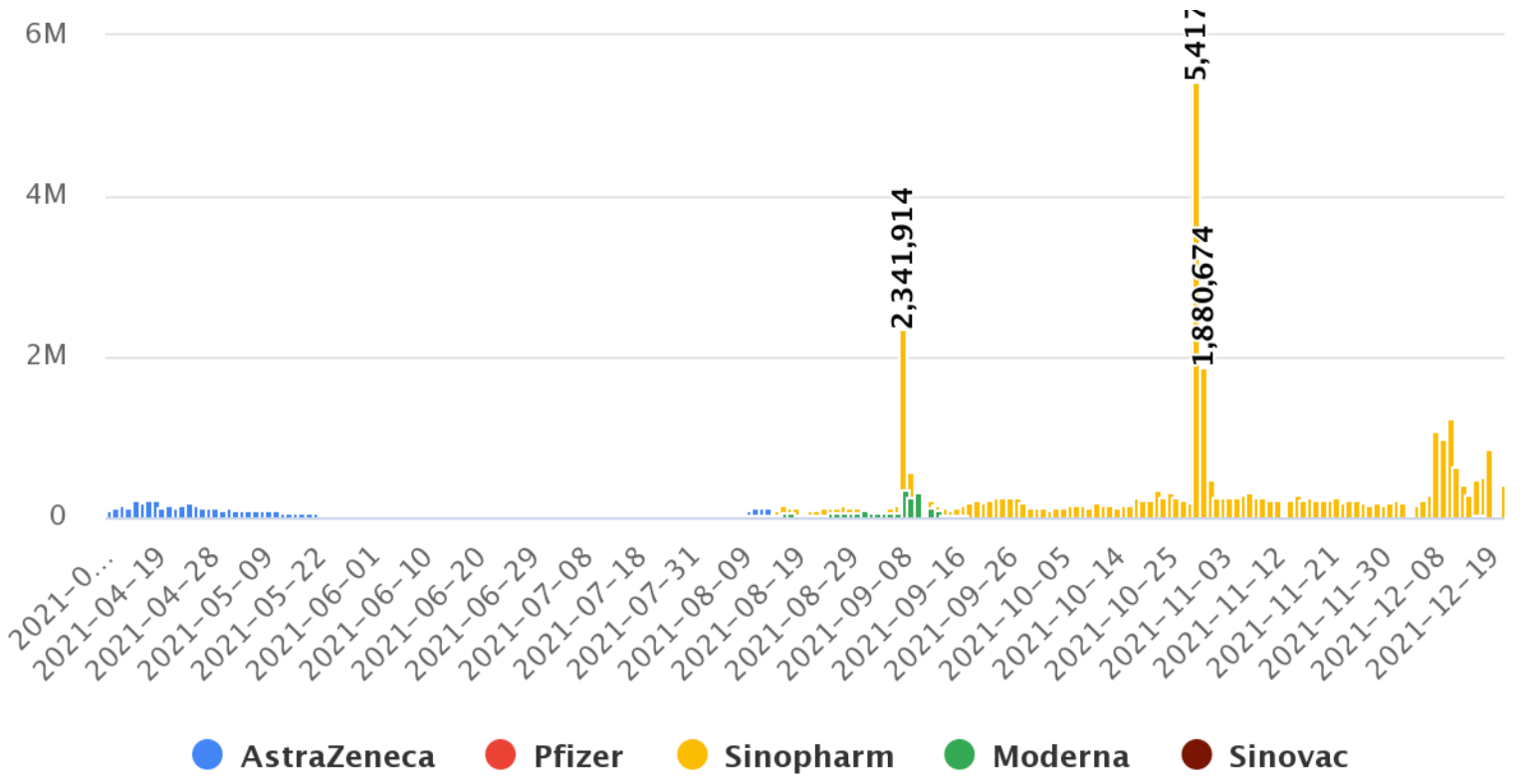

Figure 2. The $2^{\text {nd }}$ Dose Vaccines Administered in Bangladesh

Source: Covid19 vaccine Dashboard, 2021 


\section{Literature Review}

The literature review consists of various significant moments of vaccine procurements of Bangladesh.

China-Bangladesh-India a Triangle of Geopolitical Diplomacy. At the begging phase of Covid-19, China expressed their interest to conduct a phase-3 trial of their Covid-19 vaccine (Chaudhury, D. R., 2020). Connecting to that event Bangladesh Medical Research Council (BMRC) expressed their approval and China sent a medical team to Bangladesh to assess the pandemic situation. Just after weeks of these events, India the closest neighbor assured that Bangladesh will get the Covid-19 vaccine on a priority basis and pharmaceutical companies of Bangladesh will be able to collaborate on the process (Bhattacherjee, K., 2020).

On the other hand, Indian Foreign Secretary Harsh Vardhan Shringla, on 19 August 2020, reassured the vaccine priority issue. Bangladesh offered to extend the assistance by providing the trail of the Oxford-AstraZeneca vaccine in Bangladesh if needed (The new Indian express 2020a). On 28 August 2020, the hope came with the news that Bangladesh's Beximco Pharmaceuticals is about to invest in Serum Institute India (SII) for the Oxford-AstraZeneca covid-19 vaccine but the number of doses or the amount of investment was yet not confirmed (Paul, R., 2020; Gupta, S., 2020).

India's "vaccine diplomacy" came at the same time when its strategic rival, China through Chinese Ambassador in Dhaka Li Jiming, have proposed Bangladesh to be the "first volunteer" for a phase three trial of the Chinese Sinovac vaccine, according to China's nationalist tabloid Global Times on 27 August 2020 (Dasgupta, D., 2020). In September 2020, Chinese Sinovac informed that Bangladesh needs to co-finance to initiate the trial run. In response, Abdul Mannan, the health division secretary of Bangladesh, stated that Sinovac never talked about the 'co-finance' issue before so, the decision will be taken after consulting with relevant authorities (The economic Times, 2020a).

30 Million Vaccine Deal with Serum Institute of India (SII). 5 November 2020 was a momentous day in vaccination issue as on that day, Bangladesh Beximco Pharmaceuticals ltd signed a 30 million covid-19 vaccine deal with Serum Institute of India. Regarding the deal, Health minister Zahid Maleque said that with the help of Bangladesh's Beximco pharmaceuticals, 5 million doses of vaccine will be bought every month at $\$ 4$ to $\$ 5$ per dose. To secure the funds, Bangladesh also had talks with World Bank and the Asian Development Bank. Bangladesh at that time also refused the 'Co-finance' offer by Sinovac of China, which led to uncertainty of Sinovac Biotech's late-stage trial of a potential coronavirus vaccine in Bangladesh (Reuters. 2020)

COVAX Opportunity and Barriers to Avail the Mrna Vaccines. Bangladesh's government confirmed in December 2020 that the country would procure 60 million vaccines through the United Nations' COVAX program by May-June 2021 (Shawon, A., 2020). By this time, trials of mRNA technology-based vaccines Pfizer-BioNTech and Moderna succeeded in trials, but as these need to be stored at minus 70-80 degrees Celsius temperature, Bangladesh finds it challenging to procure these vaccines compared to its available cold chain facility at that time. Bangladesh has a capacity of cold chain capacity at temperatures as low as minus 20-degree Celsius under the Expanded Programme on Immunization (EPI) framework for preserving lifesaving drugs and children's vaccines. Health Services Division Secretary Abdul Mannan said that the country is not thinking about the procurement of Pfizer and Moderna vaccines because these are not suitable for Bangladesh due to temperature-related problems. Former director (disease control) of the DGHS Be-Nazir Ahmed added that not only storage the aircraft needed for the transportation is very few (Prothom Alo, 2020a).

Beximco to Sell Astra Zeneca Vaccine. A bit of controversial news came at the start of the year 2021 that Beximco pharmaceuticals will purchase Oxford-AstraZeneca vaccine from Serum Institute India and will be selling it privately in the Bangladesh market. It will be different from the deal where the Bangladesh government purchases it for a subsidized mass-vaccination program. The Bangladesh government purchased the vaccine at $\$ 4$ per dose. In contrast, Beximco must buy at $\$ 8$ per dose and it was about to sell this in the market at about 1,125 takas (\$13.27) per dose by Beximco's chief operating officer (COO). Although at the initial stage, the company will be paying $\$ 4$ per dose under the Bangladesh government program, they said that this will be adjusted later (Sumon, S., 2021b).

Vaccine Arrival. The first vaccine arrival came as a gift from India on January 21, 2021, including 2 million doses of the Oxford Astra Zeneca vaccine produced by the Serum Institute. Later on, 25 January 2021, another 5 million doses of the same vaccine arrived as a part of the 30 million contract with Serum Institute. The vaccines were taken to a warehouse of private Beximco Pharmaceuticals Ltd. at first to check the efficacy because of temperature fluctuation and expiry date. After the proper examination, they were distributed to 64 administrative districts where 7,344 distribution teams of 42000 trained health workers were ready to 
administer the doses (Rahman, A., 2021). In an interview, Beximco Group's Vice-Chairman and Premier's Private Industry and Investment Affairs Adviser Salman F Rahman said Prime Minister Sheikh Hasina's foresightedness for the early availability of the inoculates on a massive scale in Bangladesh compared to most other countries in the neighborhood and elsewhere is the reason behind such quick procurement of vaccine (Dhaka Tribune, 2021b).

The Inauguration of Vaccination. People of Bangladesh found relief when the vaccination campaign was inaugurated in Kurmitola General Hospital of the capital on 27 January 2021 with the Serum Institute's Oxford Astrazeneca vaccine. The vaccine cost was subsidized by the government and given free of cost to all, and still, to date (19 December), it is free for the people (Dhaka Tribune, 2021d). The people who got preference for the first day were doctors, military officials, nurses, police, and government officials from the health sector. The first person who took it was named Runu Veronica Costa, a health worker in the same hospital. The second dose of the vaccine started rolling from 7 April 2021 with the same vaccine. (Xinhua, 2021a).

India Halts Export. India faced the second Covid19 wave between March and April 2020, when 211,853 deaths were counted by the end of April. The country has seen the highest deaths in a day, with 211,853 in total on April 30, 2021 (The Times of India, 2021). The cause of this spike is a highly contagious variant of the virus B.1.617 (Gentleman, J., Venugopal, S., Mandavilli, A., 2021). The crowded urban areas were the first affected. Later, populated rural areas also got affected, creating a huge scarcity of oxygen in hospitals and forcing the government to reinforce the lockdown (Pandey, V., Nazmi, S., 2021). At that time Indian government already has started the vaccination drive (From January) and already administered 150 million vaccine doses by April 2021 (Ministry of Health and Family Welfare, 2021; Joi P., 2021). At its highest point of vaccine demand, many states started complaining about the vaccine shortage (Arora N., Jain R., 2021). The Indian government halted the export of vaccines temporarily on 24 March 2021 (The BBC, 2021).

Bangladesh Eyes on Sputnik-V. Due to India's temporary halt of vaccine export, Bangladesh faced an uncertain situation with its vaccination campaign. At that time, Russia offered Bangladesh to co-produce vaccines as the country's production capacity is already full. Bangladesh now started looking for other sources of vaccines, including China. A government official said Bangladesh showed less interest in the Chinese vaccine earlier as WHO did not yet approve them, but now the government is keeping all options open. World bank also have informed Bangladesh that 80 lac doses of vaccine will be available under COVAX by May 2021. The government was also considering engaging private sectors to import and market expensive vaccines like Pfizer to meet the vaccine demand (BBC, 2021b).

The Chinese Vaccine Procurement and Political Circumstances. As everything was going wrong because of the vaccine crisis, China criticized Bangladesh's indecision over China's vaccine. The statement came from the China ambassador in Dhaka, Mr. Li Jiming, on 10 May 2021, where he said that China offered 500000 doses of vaccine as a gift on 3 February 2021, but Bangladesh waited about three months. Finally, it replied to receive the vaccine on 30 April 2021. According to the Chinese envoy, it was necessary to take quick action in the face of a grave challenge. The same sort of statement came earlier when a 10-member Chinese medical team with expertise came to visit Bangladesh from China and expressed their frustration over Bangladesh government's handling of the crisis and lack of emphasizing on busting the origin of coronavirus spread for the effective surveillance mechanism (Prothom Alo, 2021b). On 12 May 2021, Bangladesh received 5,00,000 doses of China's Sinopharm vaccine as a gift from China. According to Foreign Minister Dr. A.K. Abdul Momen, Bangladesh showed interest in purchasing 40 to 50 million doses of the Chinese vaccine. The minister also showed interest in the Co-production of vaccines which he said would be a "Win-Win" situation for both countries. The Chinese ambassador Mr. Li stated the event as a sign of China-Bangladesh's anti-pandemic cooperation. At the time World Health Organization (WHO) just listed the Sinopharm vaccine for emergency use and greenlighted to distribute it globally. The vaccine came at such a time when the political paradigm was significant as China cautioned Bangladesh against joining the so-called 'Anti Beijing club' -the Quad alliance, which can bring "substantial damage" to bilateral relations. Bangladesh's foreign minister responded by stating the comment as "Very unfortunate", "Aggressive" and unexpected (The Hindu, 2021a).

Bangladesh's Frantic Diplomatic Effort. According to a Reuter report on 18 May 2021, it was said that it is unlikely that India will resume vaccine export until October 2021. For completing the second dose, Bangladesh needed 1.6 million doses of the Oxford vaccine. So, the country was making frantic diplomatic efforts to procure COVID-19 vaccines from other countries, including the United States and Canada. More precisely, the foreign minister of Bangladesh requested Canadian High Commissioner to help to get 2 million doses, and the diplomats were working to secure 4 million AstraZeneca vaccines from the United States and hoping to share up to 60 million doses (Reuters, 2021). 
Appeal to the World Community. As part of its desperate efforts to get the coronavirus vaccine, Bangladesh mounted a diplomatic campaign amid fears that the B1.617.2 variant of COVID-19, already spread in India, could rapidly spread in Bangladesh. In interviews with CNN and British TV channel ITV News, Foreign Minister A K Abdul Momen appealed to the world community to get the vaccine. He described the vaccine situation as a "Crisis" and said Bangladesh is "Desperate" to get the vaccines from the US, China, Canada, Russia, and the UK. At that point, Bangladesh only had one million doses of AstraZeneca vaccine and 500000 Sinopharm vaccines left and is expecting 100,000 Pfizer vaccines from the USA (Hindustan Times, 2021a).

Chinese Vaccine Purchase and Controversy over Price Disclosure. Bangladesh faces a tremendous potential risk of COVID-19 third wave due to the harrowing situation of the neighboring county India with a sudden upsurge of cases and death in April 2021 (Daria, S. et al., 2021). Cabinet Committee on Public Purchase approved the purchase of 15 million doses of the Chinese vaccine before an incident where an official of the Cabinet Division said the price as $\$ 10$. Price disclosure of the Sinopharm vaccine sparks confusion and controversy. However, the government subsequently denied it. It upset the Chinese government as it sold the same vaccine for $\$ 15$ to Srilanka, and Bangladesh was not supposed to disclose the price (Times of India, 2021b). Foreign Secretary Masud Bin Momen later had a meeting with the Chinese ambassador. In an interview with a local TV Channel, the minister expressed his regret about this incident, saying Bangladesh's position was adversely affected by this and the country in the future will not be able to procure this vaccine at that rate (Air News, 2021; The Daily Star, 2021d).

Sinopharm Second Shipment and Approval of Sinovac. China confirmed the shipment of 600,000 doses of Sinopharm Shots, which were supposed to be delivered by June 13, 2021. Meanwhile, through the diplomatic channel, the Bangladesh government is trying its best to "make things normal" regarding the price disclosure issue of May 27 regarding this vaccine (The Daily Star, 2021f; Dhaka Tribune, 2021h). On June 6, 2021, the Sinovac vaccine produced by Chinese company Sinovac Biotech has been approved as the 5th vaccine for emergency use by The Directorate General of Drug Administration (DGDA) in Bangladesh. DGDA previously approved Oxford AstraZeneca-Covishield on January 7, Russia's Sputnik V on April 27, China's Sinopharm on April 29, and Pfizer-BioNTech on May 27. The DGDA approved the application of M/s Incepta Vaccine Limited as a local agent of this vaccine (Dhaka Tribune, 2021i).

US Diplomacy to Confirm COVAX. When Bangladesh was struggling with vaccine shortage, four people played an essential role in getting vaccines from the US behind the scenes. These are cardiologists Prof Dr. Choudhury Hafiz Ahsan and Prof Dr. Masudul Hassan, nephrologist Prof Dr. Ziauddin Ahmed Sadek, and former senior UN official Mahmud Ush Sams Choudhury. Their restless efforts paved the way for getting vaccines shared by the US government through Covax. The achievement goes to the government as Foreign Minister AK Abdul Momen three months early talked with them and engaged them in this initiative. They worked with the US administration and enlisted Bangladesh in the list of 18 countries out of more than 180 countries, who will get the vaccines (Mortoza, G., 2021).

Emergency Use of Moderna Vaccine. On June 29, 2021, Bangladesh approved the emergency use of the Moderna vaccine as the country will be getting 2.5 million doses of Moderna under the COVAX program. People above 18 years of age will get the vaccine. The vaccine had to be stored in temperatures between minus 15C to minus 25C and has 95\% effectiveness (Sakib, S. N., 2021; The Daily Star, 2021g). Later, on July 3, 2021, Bangladesh received the first consignment of 2.5 million doses of Moderna covid-19 vaccines through the COVAX initiative under Joe Bided-led US government plan. Bangladesh was the first country to receive the Moderna vaccine and was about to receive 1.3 million doses in the second consignment soon (Bishay, N., 2021).

Japan Diplomacy. Bangladesh government's diplomatic effort with Japan confirmed around 3 million doses of AstraZeneca vaccine from Japan, and the first consignment of 2.45 lakh doses came on 24 July 2021. The government ensured that another 5 lac doses were coming on 30 July 2021. It was essential as 15 lac people at that time were still waiting for this vaccine for the second dose to complete (DD news, 2021).

Chinese Sinopharm's Domestic Production. On 17 August 2021, a memorandum of understanding (MoU) was signed between Bangladesh's Incepta vaccines ltd and China's Sinopharm regarding the local production of Sinopharm vaccine in Bangladesh, amounting to 5 million doses per month (Hasan, A. M., 2021)

\section{Methodology}

The fundamental purpose of this study is to review the vaccine procurement opportunities and their relation to the contemporary geopolitical paradigm of Bangladesh. Relevant works of literature consist of journal articles, government statements from multiple countries are reviewed throughout the case. Only scientific articles and 
recent articles from significant newspapers (national and international) are selected for the review process. The research is limited to the point relevant to Covid-19 vaccine procurement and associated geopolitical issues of Bangladesh. The case review includes significant statements of profound international organizations and governments from multiple countries. Considering the Covid-19 vaccination an ongoing event, the regular development and change of situation are probable.

\section{Discussion}

From the beginning of the case, it has been observed that there was a geopolitical power demonstration between India and China regarding the Covid-19 vaccine distribution in Bangladesh. At that time China first came forward with the interest to conduct a phase- 3 trial of their probable covid-19 vaccine to Bangladesh. Connecting to that event Bangladesh Medical Research Council (BMRC) expressed their approval on the issue. Then China sent a medical team to Bangladesh to assess the pandemic situation. The immediate next event is connected to Indian political rivalry. India confirmed Bangladesh to be on its priority list in terms of the Serum Institute's AstraZeneca vaccine procurement. It has been clearly expressed through Dasgupta D. (2020) statements - "India's 'vaccine diplomacy' came at the same time when its political rival China through Chinese Ambassador in Dhaka Li Jiming have proposed Bangladesh to be the "first volunteer" for a phase three trial of the Chinese Sinovac vaccine, according to China's nationalist tabloid Global Times on 27 August 2020".

Now, on the other hand, if the strategy of Bangladesh is considered, it can be visible that Bangladesh took a decent strategic move by considering India as a probable source of vaccine. The Serum Institute of India is one of the biggest manufacturers of the Covid-19 vaccine. On top of that, the neighboring country provides advantages of less transportation cost and less procurement time. Again, bringing Beiximco Pharmaceuticals was a required strategic action as Serum Institute of India is a separate entity c8not part of the Indian government. Only a company could take place in the contract. When Bangladesh with Beximco was looking forward to finalizing a deal with the Serum Institutes AstraZeneca vaccine, China started reacting on the vaccine issue. China's Sinovac took a step back from the previous offer and a counteroffer of 'Co-investment' was proposed. It has been clear that the last offer did not include a financing condition, cleared by the statement of Abdul Mannan, the health division secretary of Bangladesh - "Sinovac never talked about the 'co-finance' issue before".

In November, Bangladesh's Beximco Pharmaceuticals ltd signed a 30 million covid-19 vaccine deal with the Serum Institute of India. The country was reassured that Bangladesh will soon get the vaccines on a priority basis. Bangladesh, at this point, was able to bargain as the Indian vaccine procurement was almost confirmed. So, the country refused the Sinovac Co-finance offer and confusion arose regarding Sinovac Biotech's latestage trial of a potential coronavirus vaccine in Bangladesh. But, from a strategic point, it was not a wise decision to avoid the Chinese offer as there is a saying in portfolio finance that "Do not put all your eggs in one basket!" meaning do not invest all your money in one project. It brought risk in vaccine procurement which Bangladesh faced later. The month after the SII deal, the United Nation's COVAX vaccine procurement was also confirmed, and the Bangladesh government was assured to procure 60 million vaccines by May-June 2021. Political diplomacy is also connected with the COVAX initiative. It was visible later when Bangladesh Foreign Minister AK Abdul Momen talked with four people to work with the Biden Administration to confirm vaccine procurement. Their restless efforts were the crucial point behind the procurement confirmation but what is essential is that they played a vital diplomatic role on behalf of Bangladesh.

Around March and April 2020, India faced the second Covid-19 wave with the highest mortality a day. The highly contagious variant B.1.617 devasted the country, creating a shortage of oxygen, and more importantly, the biggest vaccine manufacturer in the world faced a vaccine shortage. As it happened, the Indian government halted the vaccine export and broke the 30 million deal they reassured. It created a significant negative impact on the Bangladesh-India political relation, which created an opportunity for China. The opportunity was essential to China, and it grabbed it by offering a gift of 500000 doses of vaccine as a gift on February 3, 2021. As Bangladesh doubted India's vaccine commitment, the country couldn't respond in time. Later, it was also criticized by Chinese ambassador Mr. Li Jiming, a soft political pressure from China. China also made a deal to sell 40-50 million doses of the Sinopharm vaccine, a win-win situation. From Bangladesh's strategic point, it was the best opportunity to grab the vaccines as COVAX vaccines were instantly unavailable, Bangladesh was at huge risk of a new variant that devasted India and the World Health Organization (WHO) just listed the Sinopharm vaccine for emergency use and greenlighted to distribute globally. But at what cost? The political paradigm was significant as China cautioned Bangladesh against joining the so-called 'Anti Beijing club' -the Quad alliance, bringing "substantial damage" to bilateral relations. Although Bangladesh's foreign minister responded by stating the comment as "Very unfortunate", "Aggressive" and "unexpected". 
The above situation discusses how significant the geopolitical paradigm is regarding vaccine procurement. The Chinese vaccines were approved when the so-called "Anti Beijing' club or the "Quad" was forming. There is a political opportunity cost for vaccine procurement. It is strong evidence of geopolitical influence in vaccine procurement. Bangladesh, at that point, already learned its lesson and understood that it's not a wise strategy to rely on a single source of vaccine. The evidence is the frantic diplomatic effort to procure vaccines from the rest of the countries. The desperate political effort is visible through the interviews of Foreign Minister A K Abdul Momen with CNN and British TV channel ITV News where he appealed to the world community to procure vaccines. He described the vaccine situation as a "Crisis" and said Bangladesh is "Desperate" to get the vaccines from the US, China, Canada, Russia, and the UK. China at that time put Bangladesh on its preference list by providing vaccines at lower prices than other countries of South Asia. The 'Price Controversy' came in front. China exported the same vaccine to another south Asian country - Sri Lanka with a higher price and closed the deal with Bangladesh with a lower price, giving the country priority. As previously said by India that Bangladesh is on its priority list; this could be a blow to that statement by showing that China also counts Bangladesh in its priority list. Although the price issue was an uncomfortable situation for Bangladesh and the Bangladeshi handled the situation by officially declining the event.

At this point, Bangladesh started benefiting from vaccine diplomacy with four patriotic people who worked with the US Biden administration and enlisted Bangladesh in the list of 18 countries out of more than 180 countries who will get the vaccines under the UN-COVAX program. This vaccine diplomacy later helped procure 2.5 million doses of Moderna and plenty of Pfizer vaccines. The Bangladesh government learned the hard lesson that political diplomacy with various countries could only reduce the vaccine procurement pressure and not put all the eggs in one basket. The evidence is the diplomatic effort with Japan government which ensured the necessary procurement of the Oxford-AstraZeneca vaccine to meet the second doses of the people who waited long after getting 1st dose of Serum's vaccine. The strong political relation with China later helped Bangladesh (Incepta vaccines) sign a memorandum of understanding (MoU) with Sinopharm regarding the local production of the Sinopharm vaccine in Bangladesh, amounting to 5 million doses per month. It implies that vaccine procurement is strongly affected by the geopolitical paradigm.

\section{Conclusion}

Covid-19 has brought unexpected social, political, and economic interruptions to the world, causing endless suffering to people's lives. To escape from this suffering, the only weapon people have is 'Vaccine'. The procurement of vaccines seems a much tougher task than developing it. The study tries to explain the tougher part by reviewing the role geopolitical paradigm in vaccine procurement. In doing so, the case of Bangladesh is being analyzed. The opening of the case reveals a geopolitical power demonstration between India and China regarding the Covid-19 vaccine distribution in Bangladesh. India's vaccine diplomacy came at the same time when its political rival proposed Bangladesh for a phase three trial of the potential Chinese vaccine. Bangladesh took a decent strategic move by considering India as a probable source of vaccine. The Serum Institute of India is one of the biggest manufacturers of the Covid-19 vaccine. When Bangladesh with Beximco was looking forward to finalizing a deal with the Serum Institutes of India, China reacted, and a counteroffer of 'Coinvestment' was proposed, which was not talked about before. So, a geopolitical war was underneath the vaccine procurement decision, which continued until India faced the devastating effect of the new variant, and China regained the political upper hand over the vaccine issue and made a vaccine purchase deal with Bangladesh. By this time, Bangladesh also faced the vaccine crisis and learned the brutal lesson that geopolitical diplomacy has to be managed to assure the vaccine procuring.

Later, Bangladesh showed excellent vaccine diplomacy in various stages with the US for COVAX vaccine procurement and later Japan for Oxford-AstraZeneca vaccines, proving that vaccine procurement is directly connected with how the geopolitical issues are handled. The research is significant because it combines the pandemic and geopolitics. Although the Covid-19 pandemic is stated as a humanitarian crisis by the great nations, it is clear that it has become an opportunity for many to influence the geopolitical paradigm. If the pandemic has to end, it is vital to distribute vaccines equally throughout the world. The research finds a relation of geopolitical influence with vaccine procurement which destroys equality and reduces the chance of ending the pandemic. This research will bring attention to this important issue and hopefully will contribute to finding a solution to the problem of procurement of vaccines to end the pandemic.

Funding. There is no funding for this research. 


\section{References}

1. Arora, N., Jain, R. (2021). India hopes U.S. Will Soon Ease Ban on Vaccine Material Exports. Reuters. 19 April. Available at: [Link]

2. Air News (2021). Controversy over disclosure of Chinese COVID vaccine pricing in Bangladesh. News on air. Available at: [Link]

3. Beigel, J.H., Tomashek, K.M., Dodd, L.E., Mehta, A.K., Zingman, B.S., Kalil, A.C., et al. (2020). Remdesivir for the treatment of Covid19-preliminary report. The New English Journal of Medicine [Internet], 383, 1813-1826. [CrossRef]

4. The BBC (2021). Coronavirus: India Temporarily Halts Oxford-AstraZeneca Vaccine Exports. Available online at: [Link]

5. BBC (2021b). Bangladesh eyes Sputnik vaccine to overcome supply shortage from India, BBC news. Available at: [Link]

6. Bhattacherjee, K. (2020). India to offer COVID-19 vaccine to Bangladesh on priority basis. The Hindu. Available at: [Link]

7. Bishay, N. (2021). COVID-19: Bangladesh Receives 2.5 Million Doses Of Moderna Vaccine From US. Republic World. Available at: [Link]

8. Chaudhury, D. R. (2020). China plans to use Bangladesh population to conduct phase III Covid-19 vaccine trails. The Economic Times. Available at: [Link]

9. Covid19 vaccine Dashboard (2021). COVID-19 Vaccination Dashboard for Bangladesh. Bangladesh Government [Official website]. Available at: [Link]

10.Daria, S. et al. (2021). The massive attack of COVID-19 in India is a big concern for Bangladesh: The key focus should be given on the interconnection between the countries. Wiley [Online]. [Google Scholar] [CrossRef]

11.Dasgupta, D. (2020). India tries vaccine diplomacy with Bangladesh, close on heels of China. The Straits Times. Available at: [Link]

12.Dhaka Tribune (2021b). How did Bangladesh get Covid-19 vaccine so quickly? Dhaka Tribune. Available at: [Link]

13.Dhaka Tribune (2021d). 8.6 million doses of Covid-19 vaccine administered in Bangladesh. Dhaka Tribune. Available at: [Link]

14.Dhaka Tribune (2021h). China to send 600,000 more Covid vaccine doses to Bangladesh by June 13. Dhaka Tribune. Available at: [Link]

15.Dhaka Tribune (2021i). Bangladesh approves Sinovac Covid-19 vaccine for emergency use. Dhaka Tribune. Available at: [Link]

16.DD news (2021). Japan sends 2.45 lakh AstraZeneca COVID vaccines to Bangladesh, 3 million doses to follow. DD news. Available at: [Link]

17.Fonseca, E.Md. et al. (2021). The politics of COVID-19 vaccination in middle-income countries: Lessons from Brazil. Social science and medicine, 281, 114093. [Google Scholar] [CrossRef]

18.Gupta, S. (2020). Bangladesh's Beximco Signs New COVID Vaccine Deal With India's SII to Ensure Priority Access. India.com. Available at: [Link]

19.Gentleman, J., Venugopal S., Mandavilli, A. (2021). India Blames Covid-19 Variant for its Pandemic Crisis. The New York Times. Available at: [Link]

20.Hasan, A.M. (2021). China Swoops into Bangladesh with a Vaccine Deal. The Diplomat [Online]. Available at: [Link]

21.Hindustan Times (2021a). Bangladesh appeals to world community for Covid-19 vaccine doses. Business Standard. Available at: [Link]

22.Jieliang Wang et al. (2020). The COVID-19 Vaccine Race: Challenges and Opportunities in Vaccine Formulation. AAPS PharmSciTech, 21(6). [Google Scholar] [CrossRef]

23.Joi, P. (2021). Gavi the Vaccine Alliance. Why is India's COVID-19 Pandemic Skyrocketing. Available at: [Link]

24.Lan, J., Ge, J., Yu, J., Shan, S., Zhou, H., Fan, S., et al. (2020). Structure of the SARS-CoV-2 spike receptorbinding domain bound to the ACE2 receptor. Nature, 581(7807), 215-220. [Google Scholar] [CrossRef]

25.Lambert, R., Shah, C., Weiner, J. (2021). The Distribution of COVID-19 Vaccines: A Geopolitical and Strategic Analysis of Southeast Asia. Available at: [Link]

26.Mortoza, G. (2021). Vaccines Under Covax: Helping homeland in hour of need. The Daily Star. Available at: [Link]

27.Ministry of Health and Family Welfare (2021). Dashboard. Available at: [Link] 
28.Paul, R. (2020). Bangladesh's Beximco Signs COVID-19 Vaccine Deal With India's Serum Institute. US News (The Reuters). Available at: [Link]

29.Pandey, V., Nazmi, S. (2021). India Coivd-19: Deadly Second Wave Spreads from Cities to Small Towns. The BBC. Available online at: [Link]

30.Prothom Alo (2020a). When can actually Bangladesh avail of COVID-19 vaccine? The Daily Prothom Alo. Available at: [Link]

31.Prothom Alo (2021b). China criticizes Bangladesh's indecision over Covid vaccine. Prothom Alo. Available at: [Link]

32.Reuters (2020). Bangladesh signs deal with India for 30 million doses of covid19 vaccines. The times of India. Available at: [Link]

33.Reuters (2021). Nepal, Bangladesh scramble to secure COVID-19 shots as India curbs exports. Reuters. Available at: [Link]

34.Rahman, A. (2021). Bangladesh receives first covid-19 vaccine consignment from India. Available at: [Link]

35.Sumon, S. (2021b). Bangladesh joins global COVID-19 vaccine race with Bangavax set for clinical trial. Arab News. Available at: [Link]

36.Sakib, S.N. (2021). Moderna vaccine gets approval in Bangladesh. AA News. Available at: [Link]

37.The new Indian express (2020a). India's COVID-19 vaccine in advanced stage, Bangladesh to get it on priority: Foreign secretary Shringla. Available at: [Link]

38. The economic Times (2020a). Chinese pharmaceutical firm seeks Bangladesh co-finance for COVID-19 vaccine trials. The economic times. Available at: [Link

39.The Daily Star (2021d). Purchase of Sinopharm Vaccine: Price disclosure sparks confusion. The Daily Star. Available at: [Link]

40.The Daily Star (2021f). Sinopharm Shots: 2nd shipment of 6 lakh to arrive by June 13. The Daily Star. Available at: [Link]

41.The Daily Star (2021g). Moderna gets emergency use authorization in Bangladesh. The Daily Star. Available at: [Link]

42.The Times of India (2021). Covid-19: India Records Highest-Ever 401,993 New Cases, 3523 Deaths. Available online at: [Link].

43.Times of India (2021b). Expensive Chinese vaccines stir hornet's nest in Bangladesh, Sri Lanka. The Times of India. Available at: [Link]

44.The Hindu (2021a). Bangladesh receives 5,00,000 doses of Chinese COVID-19 vaccine as gift. The Hindu. Available at: [Link]

45.The Visual and Data Journalism Team (2021). Covid map: coronavirus cases, deaths, vaccinations by country (BBC). Available at: [Link]

46.The Independent Panel (2021). Fifth Meeting of the Panel Meeting Report. The Independent Panel. Available at: [Link]

47.Vaccines given in Bangladesh (Covid19 vaccine Dashboard) (2021). All vaccine 1st dose administered over time. Available at: [Link]

48. Vaccines given in Bangladesh (Covid19 vaccine Dashboard) (2021). All vaccine 2nd dose administered over time. Available at: [Link]

49.Vankovska, B. (2021). Geopolitics of Vaccines: War with other Means? Available at: [Link]

50.World Bank (2021). Global Economic Prospects. Available at: [Link]

51.Wu, F., Zhao, S., Yu, B., Chen, Y., Wang, W., Song, Z., et al. (2020). A new coronavirus associated with human respiratory disease in China. Nature [Internet], 579(7798), 265-269. [Google Scholar]

52.Wang, Y., Zhang, D., Du, G., Du, R., Zhao, J. Jin Y., et al. (2020). Remdesivir in adults with severe COVID-19: a randomized, double-blind, placebo-controlled, multicenter trial. Lancet [Internet]. Available at: [Link]

53.Xinhua (2021a). Bangladesh to administer 2nd COVID-19 vaccine dose from April. Available at: [Link] 